\title{
Percepções de alunos de pós-graduação stricto sensu acerca do multiletramento
}

\section{Perceptions of stricto sensu post-graduate students about multiliteracies $^{1}$}

\author{
Eliza Adriana Sheuer Nantes ${ }^{2}$ \\ nantes@uel.br \\ Antonio Lemes Guerra Junior ${ }^{3}$ \\ junior.guerra@hotmail.com \\ Juliana Fogaça Sanches $\mathrm{Simm}^{4}$ \\ julianafogacasanches@gmail.com \\ Ednéia de Cássia Santos Pinho ${ }^{5}$ \\ ediuel@yahoo.com.br
}

Resumo: Este trabalho sintetiza os dados de uma pesquisa qualitativainterpretativa, por meio da qual buscou-se identificar as percepções de alunos de pós-graduação stricto sensu acerca do "multiletramento" e seus possíveis impactos no ensino. Após análise de suas afirmações, coletadas por meio de questionário, constatou-se que, oriundos de múltiplas áreas de conhecimento, esses alunos atrelam o conceito tanto à multiplicidade de linguagens quanto a um novo contexto de ensino-aprendizagem, em que novas práticas pedagógicas são exigidas. Isso evidencia o modo como interagem com acepções teóricas imprescindíveis para o desenvolvimento de suas pesquisas, balizadas pela proposta do programa de pósgraduação que integram.

Palavras-chave: Ensino. Linguagem. Tecnologia. Multiletramento. Práticas sociais.

Abstract: This paper summarizes the data from a qualitative-interpretative research, through which we sought to identify the perceptions of stricto sensu post-graduate students about "multiliteracies" and its possible impact on education. After analysis of their statements, collected through a questionnaire, it was found that, from multiple areas of expertise, these students connect the concept both to the multiplicity of languages and to a new teaching and learning context, where new pedagogical practices are required. The results show how they interact with theoretical meanings that are essential to the development of their research, buoyed by the proposal of the post-graduate program that they integrate.

Keywords: Education. Language. Technology. Multiliteracies. Social practices.

\footnotetext{
1 Agradecemos à Fundação Nacional de Desenvolvimento do Ensino Superior Particular (FUNADESP) e a Comissão de Aperfeiçoamento de Pessoal do Nível Superior (CAPES) pelo apoio à pesquisa.

2 Universidade Norte do Paraná (UNOPAR-PPGENS), Doutora em Estudos da Linguagem (UEL).

${ }^{3}$ Universidade Norte do Paraná (UNOPAR), Doutor em Estudos da Linguagem (UEL).

${ }^{4}$ Universidade Norte do Paraná (UNOPAR), Doutoranda em Estudos da Linguagem (UEL).

${ }^{5}$ Universidade Norte do Paraná (UNOPAR), Doutoranda em Estudos da Linguagem (UEL).
} 


\section{Introdução}

Este ano marca o fechamento de um ciclo e o início de outro, no âmbito educacional. Termina o Plano Plurianual (PPA) ${ }^{6}$ do Governo Federal, vigente de 2012 a 2015, constituído por um conjunto de metas e desafios para as políticas públicas. Dentre eles, na área educacional, no que diz respeito ao nosso objeto de estudo, destaca-se a preocupação com a formação continuada, no sentido de propiciar ao professor e, consequentemente, ao aluno, à população, o acesso às múltiplas formas de aprender, e isso compreende inserir a tecnologia e os meios digitais como ferramentas eficazes para o ensino. Contudo, um novo PPA, a ser cumprido de 2016 a 2019, entrará em vigor, com o estabelecimento de prioridades, dentre elas suprir as lacunas do plano anterior. Na área educacional, destaca-se a discussão sobre quais são os saberes necessários para o aluno do século XXI, inserido em uma sociedade globalizada e conectada.

Assim, considera-se que, em função do possível descompasso entre os saberes necessários para a vivência em uma sociedade altamente tecnológica e os conteúdos trabalhados na escola, mais especificamente com relação aos multiletramentos existentes na contemporaneidade (ROJO, 2012; 2013), premente se faz proceder a pesquisas que tenham como objetivo mapear a visão do aluno para, então, se preciso, intervir epistemologicamente.

Nesse sentido, justificamos o corpus deste trabalho, constituído de percepções apresentadas por alunos regulares do Mestrado em Metodologias para o Ensino de Linguagens e suas Tecnologias ${ }^{7}$ acerca do conceito de multiletramento e o seu impacto no ensino, visto ser essencial a sua compreensão, conforme verificaremos na seção destinada à discussão e análise dos dados.

\footnotetext{
${ }^{6}$ Informações disponíveis em: <http://www.todospelaeducacao.org.br/>. Acesso em: 15 jun. 2015.

7 O Programa de Pós-Graduação em Mestrado para o Ensino de Linguagens e suas Tecnologias tem por finalidade a capacitação de professores e profissionais da educação. Tem como foco o desenvolvimento de pesquisas para responder às demandas por diferentes formas de aprender, fundamentadas na construção de novas metodologias de ensino.
} 
De posse dos dados coletados e devidamente sistematizados, propomo-nos a analisá-los e, se necessário, intervir ${ }^{8}$, no sentido de apontar um direcionamento mais adequado para algumas disciplinas ofertadas ${ }^{9}$ para a turma, reiterando ser primordial a compreensão do potencial das novas mídias, enquanto ferramentas eficazes para o desenvolvimento das práticas de letramento e multiletramento na esfera escolar (STREET, 2003; SOARES, 2002; KALANTZIS; COPE, 2008; DALEY, 2010).

Diante dessas proposições elencadas, o presente trabalho está organizado da seguinte forma: iniciaremos discorrendo sobre o conceito de letramento $e$ multiletramento, dentro de algumas vertentes teóricas; apresentaremos a metodologia de pesquisa empreendida, os sujeitos envolvidos, a sua relevância para o ensino; descreveremos como sistematizamos os dados, para, então, analisarmos as enunciações dos sujeitos. Finalizamos com as nossas considerações finais, além das referências nas quais ancoramos nossa argumentação.

\section{Fundamentação teórica}

A origem do termo "multiletramento" - multiliteracies - é fruto dos debates realizados por um grupo de pesquisadores de língua inglesa acerca dos letramentos $^{10}$. Em virtude de a cidade New London ter sediado o evento, no meio da década de 1990, o conjunto de estudiosos ficou conhecido com o nome Grupo de

\footnotetext{
8 São ofertadas disciplinas ao longo do curso que, se necessário, permitem adequações, reformulações, aprofundamentos, pois comportam o conteúdo em sua ementa. Dentre elas, por exemplo, no primeiro semestre, oferta-se "Ensino, Tecnologia e linguagens: aspectos teóricos e metodológicos", na qual se trabalham conceitos iniciais de letramento, multiletramento e cibercultura, bem como a questão da leitura; no segundo, oferta-se "Ambientes Virtuais de Aprendizagem", cujo enfoque é a prática utilizando-se a tecnologia como ferramenta, e "Gêneros multimodais e multiletramentos", que procura retomar e aprofundar conceitos de forma a atrelar teoria e prática.

9 Discussões atreladas à linha de pesquisa 2, "Ensino de Linguagens e suas Tecnologias", cujos objetivos são: investigar os processos de ensino-aprendizagem em ambientes presenciais e virtuais; aprofundar os estudos dos processos metodológicos, suas linguagens e tecnologias e a apropriação desses elementos no espaço escolar; discutir o trabalho colaborativo, a dialogicidade, a avaliação processual e a investigação do potencial do uso pedagógico de ferramentas no processo de ensinoaprendizagem, além de sua interação com as novas mídias e linguagens nas situações de ensino.

${ }^{10}$ Segundo dados constantes no New London Group (2000), dentre os pesquisadores que fizeram parte do encontro, em New London (Connecticut/EUA), temos: (a) Courtney Cazden, James Paul Gee e Sarah Michaels (EUA); (b) Bill Cope, Mary Kalantzis, Allan Luke, Carmen Luke e Martin Nakata (Austrália); (c) Gunther Kress e Norman Fairclough (Grã-Bretanha).
} 
Nova Londres (GNL). O resultado dessa "ebulição" de saberes foi sistematizado em forma de um manifesto conhecido, segundo Rojo (2012, p. 12), como A pedagogy of multiliteracies - designing social futures ("Uma pedagogia dos multiletramentos desenhando futuros sociais").

Uma das proposições elencadas nessa pedagogia é o papel da escola frente a dois fatores: as Tecnologias da Informação e da Comunicação (TIC) e a cultura. Em relação às TIC, o debate é sobre a premência de se assumir que elas estão presentes na prática social do educando, por conseguinte, não deveriam ser ignoradas pela instituição escolar. Quanto à cultura, trata-se da constatação de que, em sala de aula, já há uma grande diversidade cultural, logo é necessário que esse fator seja contemplado no currículo escolar ${ }^{11}$, pois faz parte das questões presentes no "mundo globalizado", sendo papel da escola combater a "intolerância na convivência com a diversidade cultural ${ }^{12}$, com a alteridade" (ROJO, 2012, p. 12).

Em busca das origens do termo "multiletramentos", deparamo-nos com as asserções de Rojo (2012), nas quais a autora postula que o GNL, ainda na década de 1990, há mais de vinte anos, observava que os jovens interagiam com

[...] outras e novas ferramentas de acesso à comunicação e à informação e de agência social que acarretavam novos letramentos, de caráter multimodal ou multissemiótico. Para abranger esses dois "multi" - a multiculturalidade característica das sociedades globalizadas e a multimodalidade dos textos por meio dos quais a multiculturalidade se comunica e informa, o grupo cunhou um termo ou conceito novo: multiletramentos (ROJO, 2012, p. 13, grifo da autora). ${ }^{13}$

\footnotetext{
11 O Projeto de pesquisa "Gêneros discursivos: uma investigação das práticas de letramento e multiletramento na esfera escolar", do qual os autores deste texto fazem parte, preocupa-se em investigar e problematizar a abordagem dos gêneros discursivos (BAKTHIN, 2010) como prática de letramento e multiletramento na esfera escolar, via gêneros midiáticos (ROJO, 2012; 2013).

${ }_{12}$ Rojo (2012) destaca que o GNL é composto por pesquisadores oriundos de países nos quais o conflito cultural se concretiza em forma de confronto entre gangues, confrontos ocorridos nas ruas, furto de intolerância, cujas questões poderiam ser amenizadas se fossem objeto de discussão em sala de aula. Citamos, como exemplo, no contexto brasileiro, o caso noticiado pela imprensa dos adolescentes que colocaram fogo no índio Pataxó, Galdino Jesus dos Santos, assassinado, em 1997, sem nenhum motivo aparente (Informações disponíveis em: <http://www1.folha.uol.com.br/fol/geral/ge21041.htm>. Acesso em: 01 jun. 2015).

13 A pesquisadora ressalta que, na década atual, utilizaria, em vez de "caráter multimodal" ou "multissemiótico", o termo "hipermidiático".
} 
Da citação apresentada, urge destacar os termos "novos letramentos" e "sociedade globalizada", pois é justamente em função das transformações sociais, mais especificamente com relação ao mundo digital e sua interferência nas formas de interação humana, que ocorre a necessidade de se ampliar a definição do que vem a ser multiletramento.

Iniciemos nossas postulações recorrendo ao estudo de Rojo e Moura (2012), no qual é discutida a diferenciação entre as nomenclaturas "letramento" e "multiletramento". A primeira foi adotada, a priori, no sentido de referir-se aos letramentos múltiplos, sendo estes concebidos para indicar a existência de diversificadas práticas letradas no âmbito social, mesmo que algumas sejam privilegiadas, em determinados momentos sócio-histórico-culturais, em detrimento de outras. Com o passar do tempo, sobretudo devido à multiplicidade de gêneros presentes nas diversificadas esferas sociais, esse conceito parece não abarcar os textos que as permeiam. Já a segunda nomenclatura, o "multiletramento", apresenta uma dimensão mais ampla, visto que a sua própria definição

[...] aponta para dois tipos específicos e importantes de multiplicidade presentes em nossas sociedades, principalmente urbanas, na contemporaneidade: a multiplicidade cultural das populações e a multiplicidade semiótica de constituição dos textos por meio dos quais ela se informa e se comunica (ROJO, 2012, p. 3).

Tais asserções são corroboradas pelo fato de que houve uma ampliação considerável do conceito por incorporar questões que envolvem a diversidade cultural e a forma hipermidiática pelas quais os textos surgem, transformam-se, transmutam-se, hibridizam-se em nosso cotidiano (MARCUSCHI, 2008).

Observa-se, ainda, que a adoção conceitual está interligada ao quadro epistemológico ao qual os pesquisadores encontram-se filiados. Assim, nos estudos de Kalantzis e Cope (2008) e de Knobel e Lankshear (2007), por exemplo, o ponto de vista privilegiado é o estudo dos multiletramentos, na perspectiva sociocultural.

Os pressupostos presentes nos estudos de Kalantzis e Cope (2008) e de Knobel e Lankshear (2007) dialogam com as pesquisas de Goulart (2010), sobretudo no que tange à premência de a compreensão/interpretação dos textos que permeiam nossa sociedade contemplar aspectos culturais, políticos e sociais. 
Para tanto, necessário se faz que a esfera "escola", por exemplo, possibilite espaços reflexivos nos quais essas temáticas sejam debatidas, via interação, na busca pelo desenvolvimento/aprimoramento da leitura.

Diferentemente, vemos que, na linha de pesquisa adotada por Santaella (2007), prevalece o enfoque dos multiletramentos presentes no ambiente digital, que se materializa, mesmo que de forma "relativamente" estável, no sentido bakhtiniano do termo, em diferentes mídias ${ }^{14}$. Nas palavras da pesquisadora, "já não há lugar, nenhum ponto de gravidade de antemão garantido para qualquer linguagem, pois todas entram na dança das instabilidades" (SANTAELLA, 2007, p. 24).

Embora nosso grupo de pesquisa não compreenda o termo "multiletramento" filiado a uma única corrente epistemológica, para este artigo, em virtude das discussões que serão arroladas na análise, a qual tem por intuito mapear a visão de alunos da pós-graduação stricto sensu acerca dos multiletramentos, além das asserções anteriormente apresentadas, recorreremos, também, às postulações de Cope e Kalantiz (2008).

Em seus estudos, os pesquisadores refletem acerca do papel da escola frente aos novos multiletramentos que permeiam a contemporaneidade, tanto no cotidiano como no mundo do trabalho. Dentre os aspectos destacados, a questão da aprendizagem ocupa um papel central, visto que ela ocorre tanto na esfera escolar como fora dela (no cotidiano).

Nesse sentido, a reflexão que permeia a questão dos multiletramentos vem atrelada à necessidade de criar-se, no espaço escolar, contextos motivadores que despertem no aluno o desejo pelo aprender. Isso deve ser feito de tal forma que sejam apontados caminhos que possibilitem a (re)construção de saber(es), no sentido de o docente, via mediação, indicar novas e diferentes possibilidades da construção do(s) conhecimento(s) disponível(eis) e de fácil acesso na contemporaneidade, em virtude de estarmos inseridos em uma sociedade globalizada, dentro da qual impera a cultura digital.

Considerando, nesse sentido, que os alunos investigados propõem pesquisas ligadas à articulação da tríade ensino - linguagens - tecnologias, base do programa de pós-graduação stricto sensu ao qual estão vinculados, é essencial que

\footnotetext{
${ }^{14}$ Nas acepções de Santaella (2007), entende-se "mídia" de forma ampla, envolvendo a mídia, a multimídia e a metamídia (para uma visão aprofundada, ver SANTAELLA, 2007).
} 
verifiquemos como eles lidam com os conceitos que balizam essas reflexões no âmbito do multiletramento.

\section{Procedimentos metodológicos}

A pesquisa aqui apresentada, como mencionado, destina-se à verificação da percepção de alunos de pós-graduação stricto sensu acerca do conceito de multiletramento e seu impacto no ensino. Assim, embora considere alguns dados quantificáveis, é recoberta por um caráter predominantemente qualitativointerpretativo, uma vez que é delineada pela análise de posicionamentos subjetivos que evidenciam o modo como esses alunos, oriundos de diferentes áreas, avaliam o impacto das novas tecnologias no ensino contemporâneo.

Os dados foram coletados por meio de um questionário (Anexo A) aplicado a 24 alunos de uma turma ingressante, no ano de 2015, no Programa de PósGraduação em Metodologias para o Ensino de Linguagens e suas Tecnologias, em nível de Mestrado, da Universidade Norte do Paraná, situada em Londrina-PR, em um processo que constituiu as atividades iniciais da disciplina "Ensino, tecnologia e linguagens: aspectos teóricos e metodológicos"15.

Os questionamentos direcionados aos alunos propiciaram reflexões ligadas: à sua multiplicidade de áreas de formação e atuação profissional; ao seu tempo de atuação em atividades de docência; ao seu contato prévio com estudos que relacionam ensino e tecnologia; às suas intenções de pesquisa, com vistas à articulação da tríade ensino - linguagens - tecnologias; às suas percepções sobre o conceito de "multiletramento"; e ao modo como concebem a escola e a formação do professor sob o impacto das novas tecnologias.

As respostas atribuídas, especificamente, ao questionamento "O que você entende por multiletramento?" foram avaliadas com base em seu conteúdo, o que permitiu uma categorização prévia das percepções dos alunos investigados acerca do conceito e seu impacto no ensino, a partir de traços de similaridade: (i)

\footnotetext{
${ }^{15}$ Primeira disciplina cursada pelos alunos, após seu ingresso no curso, ministrada pela Prof. ${ }^{a}$ Dra. Eliza Adriana Sheuer Nantes, que integra o grupo de autores do presente artigo e coordena o projeto ao qual a pesquisa está vinculada.
} 
multiletramento enquanto "combinação de múltiplas linguagens", o que caracteriza as diferentes manifestações textuais circulantes na contemporaneidade; (ii) multiletramento enquanto "novas formas de ensinar e aprender", estabelecendo uma nítida associação entre tecnologia e ensino.

A seguir, portanto, essas percepções serão apresentadas, por meio da seleção de fragmentos textuais registrados pelos alunos, considerando essas duas direções de análise, de modo a verificar como eles, atuantes em diferentes áreas, concebem as práticas de multiletramento. As análises serão complementadas com a apresentação de dados adicionais que permitem uma reflexão mais ampla sobre o seu posicionamento.

\section{Análise e discussão dos dados}

Conforme apontado previamente, 24 alunos de pós-graduação stricto sensu foram investigados, por meio de um questionário, a fim de que fossem captadas as suas percepções acerca do conceito de multiletramento e o seu impacto pedagógico. A observação de seu perfil propicia, antes da discussão que norteia o estudo, reflexões que podem corroborar possíveis asserções.

Entre os sujeitos investigados, conforme mostra o Gráfico 1, a grande maioria (16 sujeitos) é relativamente jovem, com menos de 40 anos de idade, com destaque para 4 deles, cujo ingresso no mestrado ocorre ainda antes dos 30 anos. Prevalece, também, o sexo feminino (15 respondentes). Isso vai ao encontro de dados apontados, por exemplo, pelo Painel Lattes (2015), segundo os quais o Brasil conta hoje com mais de 44 mil mestres do sexo feminino (mais de $50 \%$ do total) e pouco mais de 38 mil mestres do sexo masculino, o que denota, talvez, a maior procura, por parte das mulheres, por cursos de pós-graduação, especialmente em se tratando da área do ensino. Além disso, segundo o Painel Lattes (2015), mais de $50 \%$ dos mestres brasileiros, no Brasil, têm entre 20 e 39 anos.

Gráfico 1: Idade e sexo dos sujeitos investigados. 


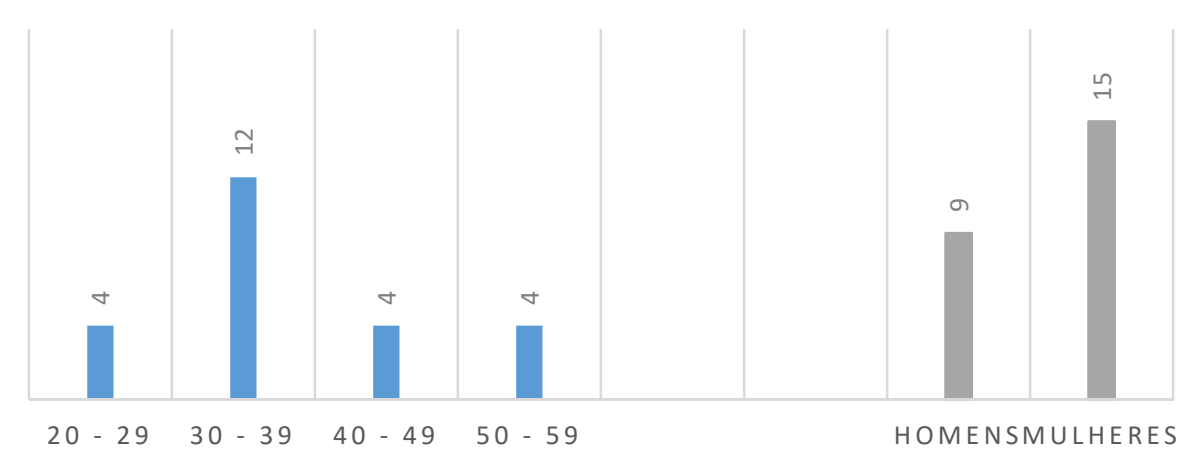

Fonte: Dados da pesquisa.

É importante registrar, nesse contexto, que a graduação dos sujeitos investigados, na grande maioria (19 sujeitos), é recente, finalizada depois do ano 2000, com destaque para três deles, graduados nos últimos cinco anos, conforme aponta o Gráfico 2. Essas informações corroboram os dados trazidos pelo Portal Lattes (2015), os quais evidenciam, como mencionado há pouco, a prevalência de mestres jovens, o que nos permite inferir que, no país, tem se tornado comum o ingresso cada vez mais cedo em cursos de pós-graduação ${ }^{16}$.

Gráfico 2: Tempo de formação dos sujeitos investigados.

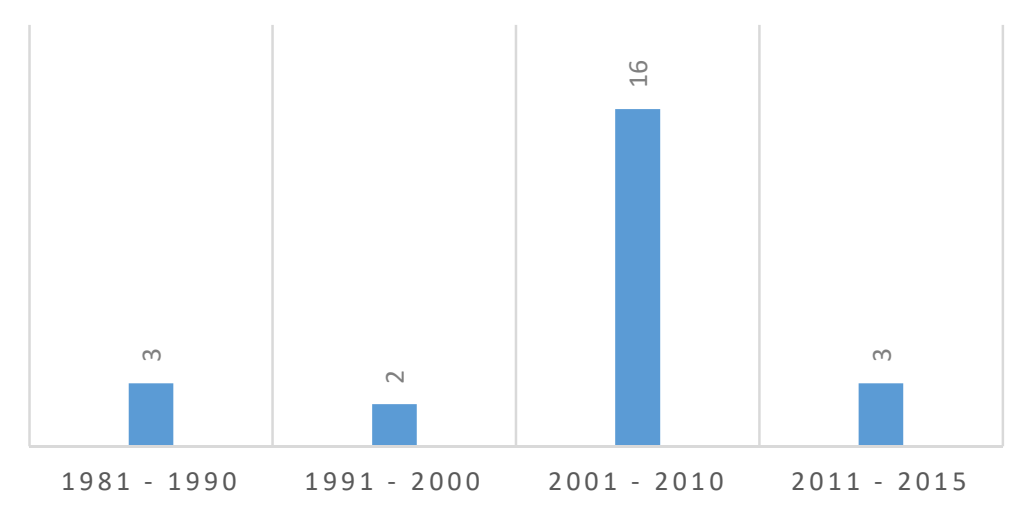

Fonte: Dados da pesquisa.

\footnotetext{
${ }^{16}$ Ver, por exemplo, as reportagens "Mestrado acadêmico: melhor hora para pós é logo após a graduação" (IWAKURA, 2007) e "Cresce o número de jovens no mestrado" (LOPO, 2013).
} 
Todos esses dados, ligados ao caráter relativamente jovem do grupo de investigados e à recentidade de sua formação, permitiram-nos uma reflexão inicial acerca da possibilidade de eles terem participado de um processo de formação teórica moldada por discussões ligadas ao impacto da tecnologia no ensino. Em outras palavras, esperava-se que, por esse motivo, fossem grandes as chances de detectarmos percepções, na maioria, condizentes com o que preconizam os estudos acerca do multiletramento (COPE; KALANTIZ, 2008; ROJO, 2012; ROJO; MOURA, 2012).

Essa expectativa, no entanto, acaba sendo confrontada com dados relativos à sua área de formação, em que é percebida a multiplicidade de cursos de graduação nos quais iniciaram seus estudos, conforme apresenta o Gráfico 3 , denotando uma possibilidade de divergências conceituais, sintetizadas nas duas categorias de análise já mencionadas (multiletramento enquanto multiplicidade de linguagens e multiletramento enquanto novas formas de ensinar e aprender). Destaca-se, nesse conjunto, o curso de Administração, com cinco sujeitos, seguido de Pedagogia, com três, Artes Visuais, Marketing e Propaganda e Processamento de Dados, com dois indivíduos cada, e outros com apenas um representante (Ciências Biológicas, Comunicação Social, Direito, Engenharia Elétrica, Fisioterapia, História, Letras, Música, Psicologia e Serviço Social).

Gráfico 3: Áreas de formação.

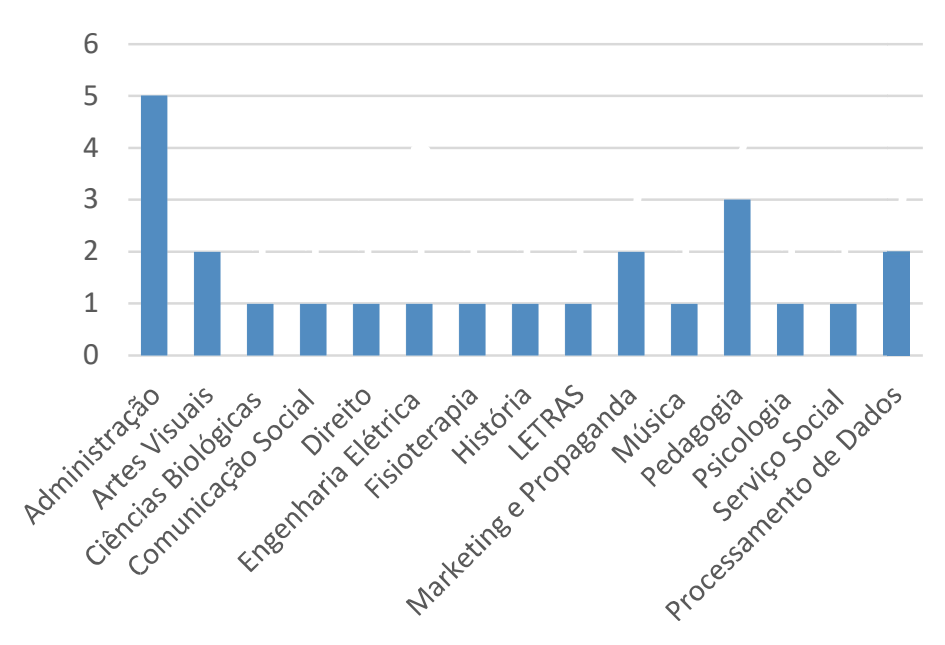

Fonte: Dados da pesquisa. 
Essa heterogeneidade, ao mesmo tempo em que acaba por determinar díspares percepções, corrobora o caráter multidisciplinar do programa de pósgraduação dos quais os sujeitos fazem parte, uma vez que o curso comporta pesquisas em ensino ligadas a diferentes áreas do saber. Além disso, é válido apontar a presença de apenas um representante da área da linguagem (sujeito graduado em Letras), o que permite a asserção de que reflexões sobre o multiletramento não se restringem a profissionais inseridos nesse campo.

Ainda nesse contexto, vale ressaltar que, embora poucos tenham cursado licenciaturas ou cursos ligados especificamente ao ensino, quase a totalidade dos sujeitos investigados atua como docentes (Gráfico 4), especialmente no Ensino Superior, o que justifica, aparentemente, o interesse pelo mestrado, a partir do qual podem desenvolver suas pesquisas ligadas à área educacional, corroborando os dados apresentados pelo Painel Lattes 2015).

Gráfico 4: Atuação na área do ensino (docência).

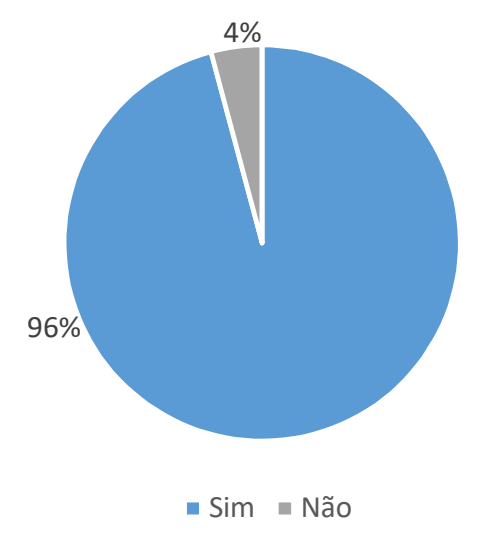

Fonte: Dados da pesquisa.

A partir desse estabelecimento de relações entre a formação dos sujeitos investigados, sua área de atuação e o seu interesse pela proposta do mestrado, que articula a tríade ensino - linguagens - tecnologias, é válido destacar que nem todos já haviam estudado a associação entre ensino e tecnologia previamente. De acordo com o Gráfico 5, 54\% deles estão participando de discussões formais - no âmbito da pesquisa - a respeito dessa articulação pela primeira vez, com o seu ingresso no curso. Esse "ineditismo" no currículo dos respondentes pode ser tomado como um 
reflexo do desenvolvimento recente de pesquisas sobre o impacto das novas tecnologias no ensino, detectável na efervescente produção científica na área e na instauração de cursos de pós-graduação - lato e stricto sensu - no país (como é o próprio caso do Mestrado em Mestrado em Metodologias para o Ensino de Linguagens e suas Tecnologias, da Universidade Norte do Paraná, cujas atividades tiveram início em 2007).

Gráfico 5: Estudo prévio sobre as relações entre ensino e tecnologia.

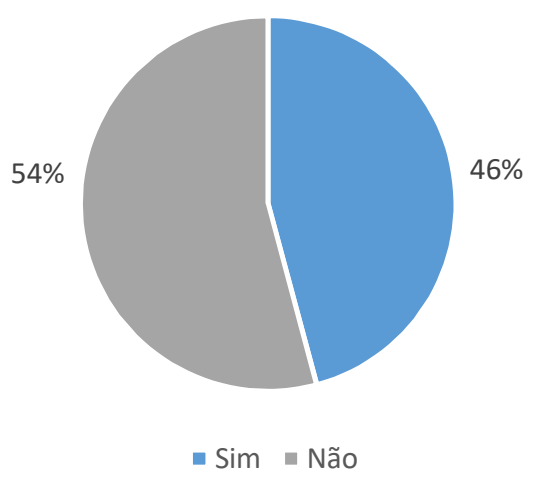

Fonte: Dados da pesquisa.

Diante desse cenário, composto, essencialmente, por profissionais docentes de diversas áreas, sem experiência na área de ensino e tecnologia, surgem algumas questões: (i) como esses sujeitos concebem o "multiletramento", um conceito fundamental para o desenvolvimento de suas pesquisas? (ii) como avaliam o impacto desse fenômeno no ensino contemporâneo? Tais indagações são respondidas à medida que observamos o posicionamento desses alunos acerca do multiletramento.

Basicamente, conforme já adiantamos, a partir da análise das percepções dos sujeitos, considerando-se traços de similaridade entre as respostas, são percebidas duas direções de reflexão, as quais nos permitem duas categorizações acerca do conceito:

1) multiletramento enquanto "combinação de múltiplas linguagens";

2) multiletramento enquanto "novas formas de ensinar e aprender". 
$\mathrm{Na}$ primeira categoria de percepções, constatamos uma reflexão superficial, genérica, segundo a qual o multiletramento está atrelado apenas à existência, na atualidade, de diferentes manifestações textuais que comportam a movimentação de diferentes linguagens, diversificados códigos semióticos ou elementos de comunicação, como evidenciam, por exemplo, as seguintes passagens:

"Multiletramento é a habilidade de interpretar a língua em suas diferentes representações."

"São múltiplas formas de linguagem, o qual inclui a tecnologia além do ato da escrita e leitura em 'papéis'."

Tais definições ancoram o conceito de multiletramento à existência de multilinguagens, diferentes representações ou manifestações da língua, ultrapassando os limites da fala e da escrita. A diversidade de áreas envolvidas na pesquisa nos leva a crer que essa ideia circula amplamente na sociedade, pois é partilhada, em certa medida, por boa parte do corpo entrevistado. Porém, de acordo com Rojo (2012), se os recursos midiáticos ou tecnológicos não forem utilizados com intenções claras e articuladas, pouco resultado será obtido no que tange à compreensão mais ampla do significado.

O posicionamento de outro sujeito repete a visão apresentada de multiletramento enquanto "modos variados" de linguagem, no entanto sua reflexão vai além, ao trazer para a discussão, também, o conceito de variação linguística:

"O Brasil é muito grande e, por ter essa característica, apresenta variações linguísticas e culturais que precisam ser levadas em consideração. Então, o multiletramento é isto: saber negociar, compreender, interpretar essas diferenças no dia a dia de sua prática profissional. Outra questão importante se refere à gama cada vez maior de recursos disponíveis de linguagem e tecnologia; nesse sentido, temos que considerar os modos variados de escrita, movimentos, imagens, áudio." 
Essa percepção corrobora o que afirma Rojo (2012), ao enfatizar que a escola deve preconizar, em suas ações, o incentivo à tolerância e ao respeito frente às inúmeras culturas, fator que engloba, inclusive, as diversas formas de manifestar a Língua Portuguesa. O preconceito linguístico é, mesmo de forma velada, parte constituinte da sociedade, que considera a apropriação e o domínio da língua padrão como um dos fatores de ascensão social. Assim, é inegável que o trabalho escolar necessita abranger, de forma efetiva, questões voltadas para a diversidade de falares, além de habilitar o educando para as suas práticas sociais cotidianas. No entanto, o respondente não articula a variação linguística ao contexto escolar, tampouco contempla a perspectiva apresentada por Knobel e Lankshear (2007), cujos estudos perscrutam o multiletramento na perspectiva sociocultural. Então, nessas asserções, tem-se o letramento limitado às reflexões circunscritas à "prática profissional".

Ainda com base nas respostas coletadas e agrupadas nesse primeiro conjunto, temos a concepção de multiletramento como a combinação de múltiplas linguagens voltadas para a construção do sentido. Desse modo, inferimos que as respostas balizadas por essa definição consideram a importância de pensar o multiletramento como parte essencial para uma melhor compreensão do texto, ou seja, atrelando a função social ao significado, com o intuito de levar o indivíduo a refletir sobre as reais intenções do texto recebido ou produzido. São exemplos dessa perspectiva:

\footnotetext{
"Multiletramento me remete à diversidade linguística e à sua importância para que ocorra um entendimento ou leitura de mundo. Entendemos os significados através de modos variados - escrita, imagens, movimento, áudio..."
}

"Multiletramento não significa somente produzir textos verbais, orais ou escritos, mas é acessar todos os meios de linguagem para produzir um conteúdo: vídeos, imagens, figuras, gráficos, textos."

Para Goulart (2010), precisamos ir além da interpretação simples dos textos, levar à reflexão sobre os significados culturais, políticos e sociais de cada discurso e mostrar que cada texto tem um objetivo, alertar sobre quem ele está beneficiando ou 
a quem está dirigindo-se, afinal, como salienta o autor, "aprender a ler e a escrever envolve circunscrever e especificar, além de alargar e fazer crescer o universo de sentidos na linguagem e com a linguagem oral e escrita, além de outras formas de expressão"(p. 451).

No segundo conjunto de percepções, por sua vez, as reflexões propostas pelos sujeitos investigados, que elevam o multiletramento ao estatuto de "novas formas de ensinar e aprender", conectam, de algum modo, a tecnologia ao ensino, apresentando um viés que vai ao encontro de suas propostas de pesquisa.

Verifica-se, nesse conjunto, que mais da metade dos sujeitos relacionaram a prática de multiletramento ao uso das novas tecnologias. Chamam a atenção algumas respostas que convergem para o fato de o ensino ainda não ter se adaptado à necessidade de uma prática voltada ao uso das TIC, conforme apontam as pesquisas de Rojo (2012), Rojo e Moura (2012) e Kope e Kalantiz (2008), e para o desafio que as escolas têm em atender a essa nova demanda, como observamos em:

"O letramento ou formação para a linguagem, por muito tempo, fundamentou-se nas práticas que privilegiavam o uso da tecnologia da escrita. Essas tecnologias atendiam de certa forma às necessidades da educação. Com o surgimento das novas mídias, linguagens e com as tecnologias digitais, novos desafios estão diante da escola."

Esse sujeito argumenta que, no passado, o letramento era tido como o ensino das técnicas que levavam os alunos a aprenderem a ler e escrever. No entanto, com o avanço da sociedade, novas tecnologias surgiram, instaurando a necessidade de a escola adaptar-se a elas, o que é corroborado por Rojo (2012) e Rojo e Moura (2012).

Nessa mesma linha, outras respostas salientam a importância de se rever a prática docente, tendo em vista a diversidade de letramentos presentes na sociedade: 
"Não temos uma única forma de letramento. O contexto é de diversidade de linguagens e mídias, assim é preciso preparar os professores para que possam trabalhar de outras formas além do convencional "quadro e giz'."

"Em minha opinião, multiletramento está relacionado a diferentes formas de aprendizagens e ensino, podendo acontecer de forma visual, oral, interpretação de textos, e está ligado à formação de alunos e professores. Assim, acredito que os professores precisam ser mais bem preparados para esse novo contexto."

É perceptível que tais sujeitos entendem que o uso das novas tecnologias em sala de aula ainda é deficitário, pelo fato de apontarem que as técnicas antes empregadas não atendem aos avanços tecnológicos que vêm ocorrendo na sociedade e, também, pela falta de formação nessa área por parte dos professores. Essas asserções vêm ao encontro dos estudos de vários pesquisadores, tais como Rojo (2012), Rojo e Moura (2012), Cope e Kalantiz (2008) e Knobel e Lankshear (2007), os quais apontam para a necessidade de a escola incorporar práticas que contemplem os multiletramentos ao ensino, ancorando-se, inclusive, no argumento contundente de que eles já estão presentes e fazem parte das práticas sociais dos educandos. Desse modo, é indicado que a escola, via mediação dos professores, explore essas novas ferramentas que envolvem ações fulcrais, tais como o ensinar e o (re)aprender.

Dentre os sujeitos que concebem ser o multiletramento necessariamente ligado à tecnologia, há divergência de posições. Uma parte deles entende que as TIC seriam apenas ferramentas para o ensino, como observa-se, por exemplo, em:

"Diversas formas de aprendizagem, em que são adotadas várias técnicas. Ex.: vídeos, textos, etc."

"Multiletramento é a utilização de várias ferramentas de comunicação (computadores/TVs) no cotidiano de aprendizagem escolar."

"Grosso modo, entendo como utilização não apenas de materiais impressos mas utilização de mídias, rádio, TV, todo o aparato tecnológico atual para o ensino." 
Para esses sujeitos, envolver as tecnologias no ensino é, aparentemente, apenas fazer uso dos recursos em que elas circulam. As respostas não apontam para a multiplicidade de textos circulantes nesses meios, bem como para a multiculturalidade existente na sociedade e, consequentemente, nas salas de aula. Seria o fato de empregar novos recursos a partir de métodos antigos, não envolvendo, desse modo, novos saberes e usos. As pesquisas desenvolvidas por Santaella (2007) apregoam que é preciso, primeiramente, o professor conhecer os ambientes digitais para, então, de posse desse saber e das suas possibilidades interativas, usar as diferentes mídias a favor da educação.

Por outro lado, há uma parcela de sujeitos que apontaram ser necessário abordar as novas tecnologias pelo fato de comporem novas modalidades de textos, requerendo, portanto, métodos que contemplem a multiplicidade semiótica que os constituem. Nessa linha, há as seguintes respostas:

"Entendo que é incorporar as diversas mídias na prática do ensino. É uma alternativa para a compreensão do uso da linguagem mediada pela tecnologia."

"Seria a apropriação das mais diferentes linguagens existentes no mundo das mídias, não apenas decifrando códigos mas também compreendendo e interpretando correta e criticamente seus conteúdos e funções, os quais circulam nos mais diversos meios de comunicação (da mesma forma como se entende o letramento dentro da aquisição da leitura e escrita)."

"As práticas de leitura e escrita no contexto das mídias digitais."

"Penso que seja as múltiplas linguagens que utilizamos no dia a dia e que necessitam ser exercitadas, exploradas e aprendidas desde a base de interpretação e leitura."

Nesse sentido, os respondentes enfatizaram uma das vertentes que compõem o conceito de multiletramento, ou seja, o caráter multimodal dos textos, indicando, assim, a necessidade de a escola adaptar-se a novas formas de leituras requeridas pelos gêneros emergentes da diversidade cultural existente na sociedade, asserções estas ancoradas nos estudos de Santaella (2007) e Rojo (2012). 
Nas enunciações dos sujeitos, por meio de excertos como "incorporar as diversas mídias", "linguagem mediada pela tecnologia", "diferentes linguagens existentes no mundo das mídias" e "práticas de leitura e escrita no contexto das mídias digitais", destaca-se o fato de a tecnologia ser perpassada por outras linguagens que requerem modos de leitura diferenciados daqueles empregados na abordagem de textos tradicionalmente utilizados no ensino, pois se tratam de novas formas de

[...] linguagens tidas como espaciais - imagens, diagramas, fotos fluidificam-se nas enxurradas e circunvoluções dos fluxos [...] Textos, imagem e som já não são o que costumavam ser. Deslizam uns para os outros, sobrepõem-se, complementam-se, confraternizam-se, unem-se, separam-se e entrecruzam-se. Tornaram-se leves, perambulantes. Perderam a estabilidade que a força de gravidade dos suportes fixos lhes emprestava. Viraram aparições, presenças fugidias que emergem e desaparecem ao toque delicado da pontinha do dedo em minúsculas teclas. Voam pelos ares a velocidades que competem com a luz (SANTAELLA, 2007, p. 24).

Conforme asserções anteriores, trata-se da construção dos sentidos sendo tecidos por cada interlocutor, na era digital, um espaço no qual impera a cibercultura. Além disso, salientam-se as respostas que fazem uso de conceitos tradicionais para tratar a respeito do multiletramento, como em:

"Capacitar por meios convencionais ou novos a leitura, a interpretação e a investigação, gerando autonomia na apreensão do conhecimento humano."

"A evolução tecnológica proporcionou à sociedade atual uma diversidade de linguagens. As novas tecnologias de informação e comunicação possibilitam ampliar a visão de mundo, mas, para fazer essa leitura, é preciso decodificar as mensagens. Para tanto, é preciso o multiletramento."

O primeiro excerto indica que a leitura e a interpretação de textos devem ocorrer através de meios "convencionais ou novos". O sujeito, no entanto, não deixa claro se os textos que perpassam essas leituras contemplam a multissemiose 
presente nas novas tecnologias ou resumem-se aos textos escritos, comuns na era do impresso ${ }^{17}$.

Já no segundo fragmento, o sujeito afirma que a evolução tecnológica acarretou diversidade de linguagens, no entanto indica que, para a leitura dos textos que as perpassam, é necessário "decodificar as mensagens". Em outras palavras, ele resume o processo de criação de significado ao simples ato de codificar/decodificar, indo de encontro aos conceitos de letramento e multiletramento. Quanto a isso, Rojo e Moita Lopes (2004, p. 38) afirmam que o letramento tradicional (da letra) é "um tipo de letramento insuficiente para dar conta daqueles necessários para agir na vida contemporânea", o que nos leva a pensar que codificar/decodificar, apenas, não é mais suficiente.

Salientam-se, ainda, outras respostas que merecem destaque:

"Diversas formas do saber e aprendizagem que estão à nossa disposição e para as quais, muitas vezes, não damos a atenção devida. Forma interdisciplinar."

"Entendo como as novas formas de relacionamento entre as tecnologias, o ensino e a linguagem. [...] Creio que o multiletramento é como uma força intangível do século XXI, que vai invadir silenciosamente as nossas vidas, no sentido de ser necessário encontrar a linguagem correta, para abordar o ensino para o alunado."

O primeiro trecho evidencia um equívoco quanto ao que seja o multiletramento, pois considera-o como um "método" de ensino. Já o segundo excerto, apresenta um contrassenso, uma vez que o multiletramento, de acordo com os estudos na área, já é uma realidade na sociedade, não podendo, portanto, ser considerado intangível, conforme excerto "força intangível do século $\mathrm{XXI}$, que vai invadir silenciosamente as nossas vidas". Aliás, a força do multiletramento não "vai invadir" nossas vidas, pois isso já ocorreu, visto que a tecnologia digital já está

\footnotetext{
17 "Na era do impresso, reservou-se a palavra texto principalmente para referir os textos escritos, impressos ou não; na vida contemporânea, em que os escritos e falas se misturam com imagens estáticas (fotos, ilustrações, gráficos, infográficos) e em movimento (vídeos) e com sons (sonoplastias, músicas), a palavra texto se estendeu a esses enunciados híbridos de 'novo' tipo, de tal modo que hoje falamos também em textos orais e em textos multimodais" (ROJO, 2014).
} 
presente em nosso cotidiano (ROJO, 2012). Ademais, questionamos a seleção lexical "silenciosamente", pois a força da mídia e os interesses que ela carrega, inclusive na venda de produtos e/ou serviços, são ruidosamente devastadores. Voltando às enunciações proferidas, isso pode representar um desconhecimento quanto ao conceito do termo.

E essa tangibilidade do multiletramento é tão concreta que permite reflexões capazes de evidenciar a visão consciente de certos sujeitos acerca de uma evolução em curso na área do ensino, detectável, por exemplo, na seguinte enunciação:

\footnotetext{
"Entendo ser uma fusão que incorpora outros tipos de letramentos ao letramento convencional, utilizando-se uma metodologia visual, meios digitais, visuais e audíveis, entre outros que possam transmitir as demandas para que, de uma forma transparente, possamos interpretar novos arranjos de textos."
}

A seleção lexical de termos indica direcionamentos que nos permitem aferir que estamos em construção de um conceito do tradicional rumo à apropriação de novas teorias. Além disso, observa-se que a repetição do vocábulo "outros", em duas ocorrências, é altamente significativo.

No primeiro caso, admite-se que há um letramento, contudo, diante dos novos contextos sociais, são acrescidos "outros tipos de letramentos ao letramento convencional". Compreendemos que, mesmo que o enunciador não tenha feito a seleção linguística da palavra "multiletramento", ela está incorporada no fragmento, como no uso do termo "fusão", possivelmente empregado para representar a presença de novas formas que eclodem em uma "metodologia visual, meios digitais, visuais e audíveis, entre outros". Em outras palavras, o aluno retoma as "outras e novas ferramentas de acesso à comunicação e à informação" (ROJO, 2012, p. 13).

Na sequência, temos o segundo "outros", que estabelece uma ponte com "novos arranjos de textos", o que nos indica a observação da existência das pluri, múltiplas e hiperformas de construção do(s) caminho(s), incorporando os possíveis "novos letramentos, de caráter multimodal ou multissemiótico" (ROJO, 2012, p. 13), presentes em nossa sociedade contemporânea, sobretudo nas áreas urbanas, altamente conectadas, nas quais os usuários da língua fazem uso da multiplicidade 
semiótica tanto nas interações humanas como na leitura dos textos presentes nas várias esferas sociais.

\section{Considerações finais}

O objetivo do presente trabalho, como discutido, centrou-se em verificar o posicionamento de alunos de pós-graduação stricto sensu em relação às reflexões atuais em torno das transformações no ensino contemporâneo em decorrência do impacto das novas tecnologias. Nesse contexto, a partir dos dados coletados, tencionamos investigar: (i) como esses sujeitos concebem o "multiletramento"; (ii) e como avaliam o impacto desse fenômeno no ensino contemporâneo.

Inicialmente, foram reunidas as respostas dos alunos dadas ao questionamento "O que você entende por multiletramento?", as quais nos levaram a dois segmentos reflexivos: a visão de multiletramento enquanto "combinação de múltiplas linguagens"; e a concepção de multiletramento enquanto "novas formas de ensinar e aprender", sendo essa última um reflexo do modo como percebem o ensino na atualidade, exigindo novas práticas pedagógicas.

Entre o conjunto de dados e, especialmente, considerando a multiplicidade de áreas, verificamos diferentes perspectivas sobre o multiletramento, algumas mais apuradas, e outras nem tanto, embora, em certa medida, possamos extrair um posicionamento geral: o da consciência acerca da transformação no uso que fazemos da linguagem, manifestada hoje em diferentes formas, as quais moldam novos artefatos textuais e (re)direcionam as práticas de formação em leitura e escrita, as práticas de letramento.

Diante disso, considerando-se o impacto da tecnologia e das diferentes mídias na sociedade, retomamos os estudos de Cope e Kalantiz (2008) e perguntamo-nos: qual é o papel da escola nesse contexto?

Os dados coletados permitiram-nos duas direções. A primeira perspectiva, atrelada às enunciações proferidas, já apontou para a necessidade de se retomar a discussão e aprofundar a diferenciação entre letramento e multiletramento, junto aos alunos do programa de pós-graduação stricto sensu ao qual estão vinculados, visto que a concepção caminhou em direção à limitação do multiletramento enquanto 
"combinação de múltiplas linguagens", o que caracteriza as diferentes manifestações textuais circulantes na contemporaneidade. Inferimos que, em parte, essas percepções foram decorrentes da diversidade de áreas de formação de cada um, cujas grades curriculares priorizam outros saberes. Além disso, essa necessidade de retomada e aprofundamento dos conceitos mostra-se necessária, na medida em que, dentre os 24 respondentes do questionário, chegamos a um total de 20 posicionamentos para a questão "O que você entende por multiletramento?". Quatro sujeitos abstiveram-se de apresentar suas percepções acerca do fenômeno, talvez devido à sua insegurança em termos de domínio teórico, o que reitera a exigência de novas discussões a respeito.

A segunda perspectiva apontou que os alunos compreendem que há uma ponte entre tecnologia e ensino. Nesse contexto, o multiletramento é visto enquanto "novas formas de ensinar e aprender", estabelecendo uma nítida associação com a multiplicidade semiótica presente nos textos pelos quais a sociedade interage.

Assim, entendemos que, se a escola, de fato, preocupar-se com a oferta de um ensino que venha ao encontro das demandas sociais, premente se faz investir na formação de professores, possibilitando o acesso aos saberes acerca do letramento, multiletramentos e cibercultura, pois isso permitirá ao docente ver a tecnologia da informação e comunicação como uma ferramenta eficaz para o ensino almejado: um aluno crítico e reflexivo capaz de transitar em contextos diversificados nos quais imperam os textos hipermidiáticos (KALANTZIS; COPE, 2008; DALEY, 2010). Ao refletirem sobre essas transformações e sobre essas necessidades, em suas pesquisas, os sujeitos investigados demonstram certo nível de preocupação em relação a esse novo panorama educacional.

Nesse sentido, o desafio da escola perpassa pelo desafio da formação docente e discente, na qual ações como ensinar e aprender ocorrem de forma pluri, multi e hipersignificativa, em uma realidade educacional onde não impera um saber, mas sim múltiplos saberes.

Diante do exposto, retomamos as ações governamentais já propostas no Plano Plurianual (PPA) do Governo Federal para 2016, do qual destacamos a preocupação com a criação de projetos, programas e, dentro deles, plataformas de aprendizagem estruturadas, visando à exploração de objetos de aprendizagem concretizados via leitura por meio dos multiletramentos. 
Enfim, necessário se faz, para a educação do futuro, retomarmos e ampliarmos as enunciações do poeta brasileiro Thiago de Mello: "Não tenho um caminho novo, o que tenho de novo é o jeito de caminhar." Diríamos que o desafio atual dos professores, alunos e da sociedade em geral é compreender que o aprender, metaforicamente, é possível por mais de um e/ou diferentes e/ou múltiplos caminhos. Entretanto, um argumento, independentemente do caminho escolhido, é premente: é preciso "clicar", ou seja, caminhar!

\section{Referências}

BAKHTIN, Mikhail M. Estética da criação verbal. 5. ed. São Paulo: WMF Martins Fontes, 2010.

DALEY, Elizabeth. Expandindo o conceito de letramento. Trabalhos em Linguística Aplicada, Campinas, v. 49, n. 2, p. 481-491, jul./dez. 2010.

GOULART, Cecília. Cultura escrita e escola: letrar alfabetizando. In: MARINHO, Marildes; CARVALHO, Gilcinei Teodoro (Org.). Cultura Escrita e Letramento. Belo Horizonte: Editora UFMG, 2010.

IWAKURA, Mariana. Mestrado acadêmico: melhor hora para pós é logo após a graduação. Folha Online, 28 jan. 2007. Disponível em:

<http://www1.folha.uol.com.br/folha/especial/2007/guiadaposgraduacao/fj280120071 8.shtml>. Acesso em: 05 jun. 2015.

KALANTZIS, Mary; COPE, Bill. Digital communications, multimodality and diversity: towards a pedagogy of multiliteracies. Scientia Paedagogica Experimentalis, v. XLV, n. 1, p. 15-50, 2008.

KNOBEL, Michele; LANKSHEAR, Colin (Orgs.). A new literacies sampler. Nova York: Peter Lang, 2007.

LOPO, Joana. Cresce o número de jovens no mestrado. A Tarde, 08 out. 2013. Disponível em: <http://atarde.uol.com.br/pos-graduacao/materias/1539400-cresce-onumero-de-jovens-em-mestrado>. Acesso em: 05 jun. 2015.

MARCUSCHI, Luiz Antônio. Produção de texto, análise de gêneros e compreensão. São Paulo: Parábola Editorial, 2008.

NEW LONDON GROUP. A Pedagogy of multiliteracies: designing social futures. In: COPE, Bill; KALANTZIS, Mary (Orgs.). Multiliteracies: literacy learning and the design of social futures. London; New York: Routledge, 2000, p. 9-37. 
PAINEL LATTES. Distribuição por sexo, faixa etária e grande área de atuação. Disponível em: <http://estatico.cnpq.br/painelLattes/sexofaixaetaria/>. Acesso em: 05 jun. 2015.

ROJO, Roxane. Pedagogia dos multiletramentos: diversidade cultural e de linguagens na escolar. In: ROJO, Roxane; MOURA, Eduardo (Orgs.).

Multiletramento na escola. São Paulo: Parábola Editorial, 2012.

2013.

Escola conectada: os multiletramentos e as TICs. São Paulo: Parábola,

. Textos multimodais. Glossário Ceale. Disponível em:

<http://www.glossarioceale.com.br/verbetes/textos-multimodais>. Acesso em: 30 set. 2014.

; MOITA LOPES, Luiz Paulo. Linguagens, códigos e suas tecnologias. In:

BRASIL/DPEM. Orientações Curriculares do Ensino Médio. Brasília:

MEC/SEB/DPEM, 2004, p. 14-59.

; MOURA, Eduardo (Orgs.). Multiletramentos na escola. São Paulo:

Parábola Editorial, 2012.

SANTAELLA, Lúcia. Linguagens liquidas na era da mobilidade. São Paulo:

Paulus, 2007.

SOARES, Magda. Letramento na cibercultura. Educação e Sociedade, Campinas, v. 23, n. 81, dez. 2002. Disponível em: <http://www.cedes.unicamp.br>. Acesso em: 03 jun. 2015.

STREET, Brian. Abordagens alternativas ao letramento e desenvolvimento. Teleconferência Unesco Brasil sobre "Letramento e Diversidade". Outubro, 2003.

\section{Anexo A:}

Questionário aplicado aos alunos de pós-graduação stricto sensu para coleta de dados acerca de suas percepções sobre o conceito de multiletramento e das relações entre ensino e tecnologia.

1. Idade:

2. Formação:

(graduação cursada)

3. Ano de formação:

(finalização da graduação)

4. Área/empresa em que atua:

(dados sobre sua atuação profissional) 
5. Já cursou alguma especialização?

(curso de pós-graduação lato sensu)

( ) Sim ( ) Não

6. Se já cursou alguma especialização, cite-a:

7. Qual a sua proposta de pesquisa no mestrado?

(descreva, sucintamente, a ideia-base do seu projeto de pesquisa)

8. Como sua pesquisa poderá contribuir para o ensino?

(apresente, sucintamente, as contribuições esperadas)

9. Como você pretende articular, em sua pesquisa, a tríade: ensino linguagens - tecnologias?

(descreva sua proposta de articulação, de forma sucinta)

10. Você já estudou sobre as relações entre ensino e novas tecnologias antes? ( ) $\operatorname{Sim}($ ) Não

11. Quais ferramentas você usa para ler?

(cite os diferentes recursos pelos quais você realiza processos de leitura)

12. Na sua opinião, qual a importância da tecnologia para o ensino?

13. No seu cotidiano, você usa a tecnologia para quê?

14. O que você entende por "multiletramento"?

15. Diante do quadro tecnológico que se faz presente na sociedade, como você vê a escola nesse contexto?

16. Diante do quadro tecnológico que se faz presente na sociedade, como você vê a formação do professor nesse contexto? 